\section{A prestigious cosmetic dental conference}

The prestigious British Academy of Cosmetic Dentistry (BACD) is hoping to surpass the success of last year's sold-out Annual Conference. World-class speakers, inspirational lectures, interactive workshops, and endless networking opportunities await delegates this November.

Now in its sixteenth year, the BACD Annual Conference will focus on 'Delivering Excellence: Tradition vs. Innovation' Combining first-class education with an entertaining social programme, this celebrated event will cover a variety of interesting topics from digital smile design concepts and aesthetic challenges, to composite veneers, provisional restorations, CEREC systems, and much more.

Meet likeminded individuals and learn from some of the industry's top clinicians at the BACD Annual Conference 2019.

The BACD Sixteenth Annual Conference will be held on 7-9 November 2019 at the Millennium Gloucester Hotel in London.

For further enquiries about the British Academy of Cosmetic Dentistry, visit www.bacd.com.

\section{Down to the last detail}

Dentistry requires shrewd attention to detail This is crucial in the case of dental caries in order to perform accurate diagnostics.
This includes the innovative Fluorescence Mode, which enables clinicians to efficiently visualise and repair caries-infected fillings.

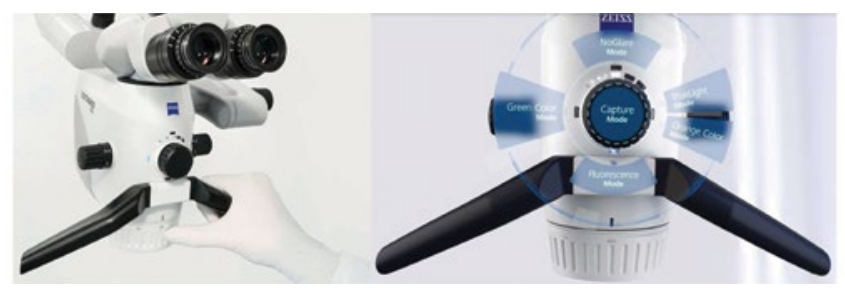

treatment, which is why Nuview supplies advanced dental microscopes from leading manufacturer, Carl Zeiss.

Modern solutions like the EXTARO 300 facilitate the delivery of high quality care by offering a unique combination of breakthrough visualisation modes.
The EXTARO 300 also saves valuable time in practice, as there is no need to interrupt workflow for visual support.

For more information call Nuview on 01453 872266, email info@nuview-ltd.com, visit www.nuview.co or 'like' Nuview on Facebook

\section{Build on your implant skills}

Are you seeking a way into the world of dental implants? Ten Dental+Facial offers a solution with its dedicated Implant Restoration Course (IRC).

This IRC is specifically designed to give you the knowledge required to diagnose and plan implant treatment, before subsequently restoring the implant once it has been placed by a trusted clinician. A modular programme taught over a year, the IRC will cover vital aspects of implant treatment, providing hands-on experience to support essential theory.

Led by Ten Dental+Facial's Dr Nikhil Sisodia and Martin Wanendeya, the IRC provides an excellent foundation for you to build on your implantology skills.

For more information about Ten Dental+Facial and the Implant Restoration Course, email office@tendental.com or call 02076227610.

\title{
Key opinion leader previews new sonic brush
}

Anna Middleton has set herself up as 'London Hygienist Ltd' and has become a multi-award winning and influential dental professional with a thriving business. She works as a key opinion leader (KOL) for leading dental companies and has a flourishing social media presence.

As one of Philips KOLs, Anna was invited to visit its world HQ in Seattle, Washington. Over two days she, along with fellow hygienist Laura McClune, were given an insight into the development of the first Sonicare toothbrush 25 years ago, as a precursor to learning about the latest Sonicare 7500 ExpertClean which is about to be launched in the UK.

This new brush is designed to guide patients to better oral care habits. Sensors track and measure brushing behaviours

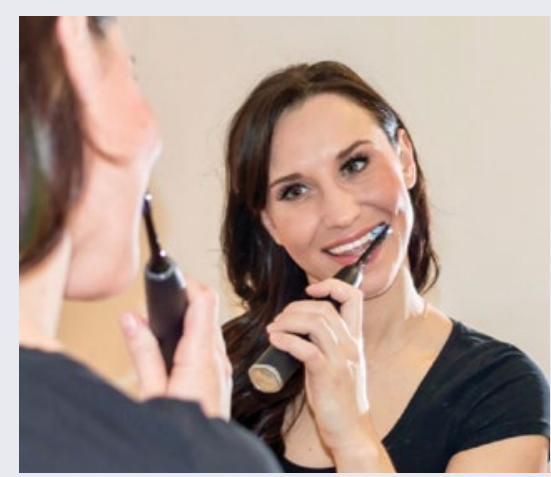

while pressure sensors in the brush handle provide instant feedback and guide the patient to adjust their brushing style. Over time, the Sonicare app retains and analyses these habits and generates a progress report for both them and their dental professional, to help develop and maintain better brushing technique.
The ExpertClean brush comes with a new head featuring soft, flexible bristles which are designed to curve around the contours of the teeth, giving four times more surface contact and up to ten times more plaque removal [than a manual toothbrush] from hard-toreach spots. Studies show that people who use this brush head have up to $100 \%$ less gum inflammation and up to $7 \mathrm{x}$ healthier gums (than using a manual toothbrush) in just two weeks. Patients would have to brush for a whole month to achieve what Philips Sonicare can do in just two minutes (an electromagnetic drivetrain inside the Sonicare handle delivers more brush strokes in two minutes than an entire month of manual brushing).

For more information about Sonicare Expert Clean: www.philips.co.uk/sonicare. 